\title{
The Common Emotional Plot of the Four Gospels
}

\author{
Cynthia Whissell \\ Laurentian University
}

\begin{abstract}
One way of defining or describing a plot is through its emotional structure. This article examines the emotional structure of the gospels of Matthew, Mark, Luke, and John in a modern English translation (WEB). Measures of emotion are based on quantitative sentiment analysis (Dictionary of Affect in Language). A common plot is identified for all gospels, modeled with a regression analysis $(p<.001)$, and described in terms of the relationship of emotion to content across time. The plot opens on an emotionally positive note. Emotions become increasingly unpleasant as Jesus meets with resistance from religious authorities while engaging in his ministry. Emotions then become more pleasant as Jesus completes his pre-Judean ministry, experiences the Transfiguration, and enters Jerusalem in triumph. After this, emotions become increasingly unpleasant again, leading to the low of the crucifixion. A turn to more pleasant emotions characterizes the resurrection. In a separate analysis it was noted that segments of the gospels presented as spoken by Jesus were more pleasant than remaining materials $(p<.001)$ : however, they did not vary emotionally in accordance with the plot $(p>.20)$, but remained relatively stable across time.
\end{abstract}

Towards the end of the $20^{\text {th }}$ century, it became more acceptable to treat and analyze Biblical materials as literature. Researchers such as Wright (1984, p. 390) and Matera (1987, p. 234) argued that a literary approach did not replace alternative approaches, that it did not deny the inspired truth of the Bible, and that it did not prevent readers from acquiring spiritual benefits when reading biblical texts. What it did do was lead to greater understanding of the texts. At about the same time, academics from different seminaries began expressing an interest in the plot of Biblical narratives such as the gospels. Kingsbury (1994) wrote about the primary conflict in Luke's gospel and Matera addressed the plot of Matthew's. Matera (1987, p. 235236) defined plot as a sequence of events, some of which were crucial and causal with respect to the action described and its outcomes, and others incidental. In his definition of plot, Matera referred to the work of Egan who stressed the importance of emotion as well as content to the description of a plot. According to Egan, "if plot is seen in terms of patterns of emotion, then to answer, 'What is the plot of X?' ... is to describe in detail the flux of emotion through the narrative" (1978, p. 456). References to the importance of emotion to plot can also be found in Aristotle's Poetics ${ }^{1}$, where, for example, Aristotle discusses the significance of a sense of decreasing fortune or happiness to tragedy (XIII).

\section{DESCRIBING THE FLUX OF EMOTION THROUGH THE GOSPEL NARRATIVES}

Emotions can, of course, be described verbally or qualitatively. They can also be measured quantitatively with techniques devoted to sentiment analysis. The aim of such techniques is to provide numerical estimates of emotion for different segments of a text or narrative. In this article a form of sentiment analysis is applied to a modern English translation of the four gospels (Matthew, Mark, Luke, and John), and the flux or flow of emotion across narrative time (represented by successive sets of words) is depicted, modeled, and discussed. The data

\footnotetext{
${ }^{1}$ Available in English translation online at http://classics.mit.edu/Aristotle/poetics.html
} 
presented in this article answer Egan's question "What is the plot of X?" with reference to emotion in the gospels.

The sentiment analysis technique employed is the Dictionary of Affect in Language (Whissell, 2009). This technique has been applied to biblical materials, for example when matching the emotionality of different chapters from various translations (there was enormous consistency, Whissell, 2012), and in an attempt to discriminate Christian from Gnostic texts (which was successful, Whissell, 2008). The technique employs a list of several thousand words which previous respondents have rated in terms of the emotional dimension of Pleasantness. The emotional nature of a text is determined by the emotional Pleasantness scores of the words within it. In recent research directed at describing the emotional plots of famous English novels (Whissell, 2018), Pleasantness scores were employed to represent the concept of "fortune" from Aristotle's theory of Poetics and to plot the "flux of emotion" throughout each novel. An example of this application is seen in Figure 1. The narrative represented here is the parable of the wasteful or prodigal son (Luke 15:11-32) from the WEB translation. ${ }^{2}$ Each point in the graph represents three verses whose contents are roughly summarized on the horizontal axis (the last point represents four verses). The parable opens with the wasteful son's request for money and ends with the father's explanation (to his older son) of his joy at the younger son's return. According to its plot, the emotional low point of the parable (the most unpleasant point) is not associated with the younger son's realization of his problems but rather with the annoyance of the older son at what he deems to be his father's preferential treatment of the younger son. Interestingly enough, a high point for Pleasantness is associated with the younger son's request for money and his "riotous living" at the opening of the parable. Emotional high points are created by the employment, within the text, of extremely positive emotional words such as "father" and "son" or "music" and "dancing". Emotional low points, on the other hand, are the result of the employment of extremely negative words such as "angry," "hunger," and "killed". Eighty-nine percent of all the words in the parable (425 of 477 words) had associated emotional scores derived from the Dictionary of Affect which were employed in the calculations that led to Figure 1.

An identical word-by-word matching approach was applied to the four gospels. Their common plot, which is explained more fully below, is presented in Figure 2.

\section{METHOD}

The translation of the gospels studied was the WEB (World English Bible) ${ }^{3}$ translation, freely available in plain text files on Project Gutenberg 4 . The files employed were identified as pg8267, pg8268, pg8269, and pg8270 (for the gospels of Matthew through John, respectively). As has been shown previously, the emotional nature of various translations of biblical materials is highly consistent across translations (Whissell, 2012), so it was assumed that the particular translation studied would not seriously impact plot.

A computer program matched the texts of the gospels word by word to the Dictionary of Affect in Language. Whenever a word from the gospels was matched to one in the Dictionary which had a value for Pleasantness (for example, the Pleasantness value for the word "hunger" in the Dictionary is 19, while that for "father" is 79), the value was imported into a data file to accompany the word. Dictionary scores for Pleasantness are represented in terms of a scale with a mean of 50 and standard deviation of 20 , so that the word "hunger" is clearly an

\footnotetext{
2 The WEB or World English Bible gospel of Luke was downloaded from http://www.gutenberg.org/ebooks/

${ }^{3}$ https://worldenglishbible.org/

${ }^{4}$ http://www.gutenberg.org/ebooks/
} 
extremely unpleasant word while the word "father" is an extremely pleasant one. Matching rates for the Dictionary are typically in the region of $90 \%$ of words (Whissell, 2009). Because the WEB translation focuses on accessible modern language, matching rates were marginally higher than this level for the gospels (91\%, 92\%, 92\%, and 94\% respectively). Ninety-two percent of the total of 80,555 words in all gospels were scored so the results discussed below are based on Dictionary matches for more than 74,000 words.

The basic units of study were chunks of 100 successive words. These chunks were larger than those employed to produce Figure 1 but were significantly smaller than gospel chapters, which tend to run to 900 words. The division of gospels into successive chunks was conducted irrelevant of the contents, verses, or chapters involved. Final chunks (those at the end of a gospel) were added to previous ones if they included fewer than 50 words. There are three strong arguments that support the choice of 100 -word-chunks: there is enough content in this number of words to allow for a description of what is being covered, and 100-word-chunks are more stable, in terms of Dictionary measurement, than shorter chunks whose emotional contents can vary widely. As well, researcher bias as to units of meaning was completely avoided by the employment of arbitrary successive chunks of equal size. Pleasantness scores were computed as averages for each chunk, with a total of 806 chunks being studied.

\section{Emotional Differences among Gospels}

\section{RESULTS}

Results of a one-way analysis of variance indicated that there were differences in overall Pleasantness among the four gospels $\left(\mathrm{F}_{3,802}=19.97\right.$, partial $\left.\eta^{2}=.07\right)$. According to a Bonferroni post hoc test, the gospel of Mark was the least Pleasant (48.32), followed by the gospels of Matthew and Luke which did not differ from one another $(49.66,49.59)$, and finally by the gospel of John which was the most Pleasant (50.09).

\section{The Common Emotional Plot of the Gospels}

The Pleasantness of successive chunks within each gospel was modeled with a binomial regression including 12 predictive terms. All gospels were treated simultaneously and their data provided a single equation. First the order of chunks within each gospel was transformed into $z$ scores so the gospels would be normalized in terms of length. For example, a $z$ score of 0 would be in the middle of each gospel, and a $z$ score of 1 would be $84 \%$ of the way through it, regardless of its original length. Then $z$ scores were raised to the $2^{\text {nd }}, 3^{\text {rd }}, 4^{\text {th }}$, and so on until the $12^{\text {th }}$ power. The 12 terms ( $z$ scores for order or place in plot and its powers) were employed to predict Pleasantness in a stepwise linear regression. Prediction was successful but weak $(R=.21)$, indicating that the model produced served to describe the emotional backbone of the gospels' plot, but also that there were many deviations from this model. The standardized predictive formula had beta weights of .31 for normalized order itself, -1.92 for the $7^{\text {th }}$ power of order, and 1.56 for the $9^{\text {th }}$ power. Prediction was significant $\left(F_{3,802}=12.38, p<.001\right)$, as were all individual predictors $(p<.001) .{ }^{5}$ The correlation between actual and predicted score was computed for each gospel separately to determine if the prediction was a better fit for some gospels than others. Correlations were $.18, .22, .25$, and .22 respectively $(p<.01$ in all cases). These correlations did not differ significantly from one another ( $z$ tests, $p>.40$ ) suggesting that the fit was similar for all gospels.

\footnotetext{
${ }^{5}$ An alternative analysis was conducted where Pleasantness scores were first standardized within gospel: a predictive scheme based on these scores produced predicted values that correlated .996 with those of the analysis employed here, in other words they resulted in a practically identical model with $R=.22$. The analysis with raw scores was retained because of the interpretability of these scores.
} 
The common emotional plot of the four gospels is represented in Figure 2. Early in the gospels there is a brief rise in Pleasantness occurring either during the infancy narrative (Matthew, Luke) or the presentation of introductory materials (Mark, John). The highest peak in Pleasantness in the gospels occurs here. There follows a drop in Pleasantness during Jesus' early pre-Judean ministry which reaches a relatively low point for Pleasantness. In Matthew this point coincides with a collection of miracles described in chapters 8 and 9 (chapter 8 includes the miracle of Jesus' calming of the violent storm and chapter 9 some criticisms of the Scribes), in Mark with the healing of the demon-possessed man, unbelief in Jesus' home town, and some miracles (chapter 5, early part of chapter 6), in Luke with the Sermon on the Plain (which contains several "woes;" chapter 6) and in John with chapter 6 (which discusses unbelief in Jesus' home town and Herod's fear of Jesus). After this low point there is a rise in Pleasantness as Jesus turns his face towards Jerusalem, with a relative peak in Pleasantness representing the beginning of his ministry in Judea. For Matthew and Mark this high point occurs close to Jesus' triumphal entry into Jerusalem (chapter 21, chapter 11), for Luke with the story of the rich young ruler (chapter 18), and for John with Jesus' discussion of the work of the Holy Spirit during the Last Supper (chapters 15, 16). Following this peak, Pleasantness declines precipitously as matters move to the arrest, trial, and crucifixion of Jesus (Matthew chapters 26, 27, Mark chapters 14, 15; Luke chapters 22, 23; John chapters 19, 20). A final rise in Pleasantness is associated with Jesus' resurrection, his appearances to the faithful, his commissioning of the disciples, and his ascension. Although the actual events being described in each gospel at any one point are not identical, the plots of all four gospels can be described in terms of the common plot in Figure 2. There is a brief rise in Pleasantness followed by a slower fall, a second rise, and a second more abrupt fall to an absolute minimum. The plot then shows an increase in Pleasantness that is associated with the resurrection.

\section{The Common Emotional Plot as a "Backbone"}

It was mentioned above that the common plot in Figure 2 represents the emotional "backbone" of the gospels. Figure 3 provides an illustration relevant to this metaphor. This figure contains two plots - the first is the backbone or common plot discussed above (darker, heavier line) and the second shows actual chunk to chunk changes in emotion for the gospel of Matthew (lighter line). The metaphor of a backbone comes from the fact that the common plot seems to support chunk to chunk variation in the same way as a spine supports ribs. As it moves up and down, points deviate from the common plot roughly equally in either direction so that Figure 2 looks rather like the spine and bones of a fish. The common plot represents the "average" of the many spikes seen in the more detailed plot. Occasionally individual chunks deviate noticeably from the common plot. Three of the most extremely pleasant and three of the most extremely unpleasant deviations are noted and numbered in Figure 3. Their exact contents are referenced and described in the note to the figure. The relatively low predictive value of the model which produced the common plot $(R=.21)$ is the result of the many deviations seen in Figure 3 . While the trend for emotional change represented by the common plot and described in the previous paragraph is accurate, small chunks of text with a particular focus such as the Lord's Prayer or the mockery of Jesus (Figure 3) might not fall into place, and might instead appear as deviations or ribs on the graph.

\section{Emotion in Words Attributed to Jesus}

Each of the chunks of text studied was scored according to whether it represented mainly words attributed to Jesus (at least $75 \%$ of words in the chunk) or not. There were 341 chunks in the first category and 465 in the second. Not surprisingly, chunks containing predominantly words attributed to Jesus were more Pleasant than those containing few or no such words (50.29 versus $\left.49.24, t_{804}=4.78, p<.001\right)$. 
One of the most unexpected outcomes of the common emotional plot discussed above was the rather obvious decline in Pleasantness during Jesus' early pre-Judean ministry and the subsequent rise in Pleasantness during the later part of this ministry (Figure 2). Did Jesus himself change the emotional tone of his language, or should this fall and rise be attributed to the narration of the text and the words of others? All gospels were subdivided into five units the introductory one (birth narrative, introduction), one associated with the early pre-Judean ministry (from the first peak in Figure 2 to the first trough), one associated with the late preJudean ministry (from the trough to the second peak), one associated with the Judean ministry, and ending in the crucifixion (from the second peak to the third trough) and a final one representing the resurrection (from the final trough to the end). No chunks in the first or introductory unit represented mainly Jesus' words, and only two in the final resurrection unit did so (Jesus spoke, but he did not speak at length in this unit).

When chunks associated with the early pre-Judean ministry were studied, those containing primarily words spoken by Jesus did not evince the downward trend seen in Figure $2\left(r_{54}=.12\right.$, $p=.36)$, while those associated with narration and with other speakers did $\left(r_{129}=-.22, p<.001\right)$. When chunks associated with the later pre-Judean ministry were studied next, the same pattern emerged. The expected rise in Pleasantness was not characteristic of Jesus' words $\left(r_{206}=.05, p=.21\right)$, but it appeared instead in the remaining materials $\left(r_{188}=.24, p<.001\right)$. Results from the third unit, which represents the Judean ministry, confirm this trend. Chunks representing Jesus' words did not change across time $\left(r_{75}=.12, p=.29\right)$, while those representing other materials did $\left(r_{108}=-.23, p=.015\right)$. The drop, rise, and drop in Pleasantness during the evangelists' account of the Pre-Judean and Judean ministries should therefore be understood as originating from the narration of the gospels and the speeches of other characters, and not from words attributed to Jesus. In fact, there were no significant differences in the average emotional tone of Jesus' speeches in the three central units (Early Pre-Judean ministry: 50.07, late Pre-Judean ministry: 50.48 , Judean ministry: $50.30 ;\left(F_{2,336}=.86, p=.42\right)$. This is not to say that words attributed to Jesus never varied in emotional tone. For example, Matthew (18:2-9) contains two adjacent chunks attributed to Jesus that differ in Pleasantness. The first (Pleasant) chunk contains Jesus' words "Most certainly I tell you, unless you turn, and become as a little child, you will in no way enter into the Kingdom of Heaven" and the second (Unpleasant) chunk contains his warning "Woe to the world because of occasions of stumbling!" Pleasantness was 51.5 for the first chunk and 47.7 for the second. It is reasonable, therefore, to conclude that words attributed to Jesus vary in conjunction with their content, but not in response to location within the narrative.

\section{Limitations of the Research}

\section{DISCUSSION}

The two most obvious limitations of this research are the particular method of sentiment analysis employed (the Dictionary of Affect in Language) and the particular translation analyzed (WEB). All methods of sentiment analysis have their limits: some assurance accompanies the use of the Dictionary because it scored so many (over 90\%) of the words in the gospels. This is due in part to the fact that the WEB is a modern, accessible, translation. It was one of the translations studied by Whissell (2012) when she noted the extreme emotional consistency across biblical translations of very different kinds. No system of sentiment analysis as yet exists that can treat New Testament Greek, so the choice made for this study was pragmatic, but not unreasonable. An additional possible limitation involves the metaphor of the backbone discussed above. At one and the same time one can legitimately claim that there is a common emotional plot describing the gospels exists, and also assert that there are many meaningful variations from this plot throughout. 


\section{Conclusions}

This study of fluctuations in emotional tone within the gospels provided some confirmatory results and some unexpected ones. Differences among gospels (with John being the most pleasant and Mark the least pleasant) are in agreement with previous results (Whissell, 2012). The fact that pleasantness decreases as we move from Jesus' triumphal entry into Jerusalem to his crucifixion can easily be understood in terms of the events described. The finding that the opening of the gospels is more pleasant than the remaining materials within them does not require much clarification. Christmas and Easter (two Holy days whose associated events are represented at the beginning and near the end of the common plot) are acknowledged to be positive celebrations, with the first possibly being more ebullient and the second more profoundly respectful (Matera, 1987, p. 242). Even the finding that Jesus' words are more pleasant than the narration surrounding them is easily explained. Jesus certainly evinced more love, patience, and understanding than the remaining "characters" in the gospels. It is also not surprising the Jesus' own words remained consistent in terms of emotion, even when the background language of the gospels changed.

Among the unexpected or surprising results is the finding that one and the same emotional backbone applies to all four gospels. The gospels are not only of different lengths; they contain stylistic differences, even if one assumes that they were addressed to a common audience of "general Christians" (Klink, 2004). The evangelists do not all relate the same events, and commonly reported events are often reported in different orders. Nevertheless, the four gospels can all be described in terms of the same emotional backbone. Their opening contents are pleasant. This pleasantness declines during Jesus' early ministry and reaches a low point. It then rises through the Transfiguration to the events of Palm Sunday, after which it falls again to its lowest point - that of the crucifixion - rising one final time in the telling of the resurrection. If one were to focus on the issue of conflict as crucial to plot, as Kingsbury (1994) suggests, they would conclude that the two points of greatest conflict in the plot were to be found at the two points of greatest unpleasantness - namely in the middle of the Pre-Judean ministry and during Jesus' trial and crucifixion. It is at the first of these low points that we see the religious authorities (Scribes and Pharisees) beginning to vigorously question Jesus' ministry, and at the second that we find a report of their seeming success in eliminating Jesus. Kingsbury (p. 371) points out that conflict between Jesus and the religious authorities "breaks out" in chapter 5 of Luke and "persists" through chapter 6 in a "cycle of controversies". Matera (1987, pp. 242, 248) notes that by the middle of Matthew's gospel (chapter 11) there is a crisis in Jesus' ministry and "it becomes probable the Israel will not accept Jesus as the Messiah". In Matthew, the first unpleasant low point occurs shortly before this: in chapter 9 we see the religious establishment criticizing and rejecting Jesus after he has healed a paralyzed man. In the gospel of John, Jesus warns his disciples, at the low point in chapters 15-16, that the world will hate them, and in Mark chapter 6 we find the death of John the Baptist pre-figuring the death of Jesus. In spite of the evident disgruntlement of the authorities, Jesus' popularity with the common crowds continued to rise, and his relationship with and teaching of his disciples continued to develop, culminating in the events of Palm Sunday. After this point the mood changes and becomes more sombre up to the point of the crucifixion.

\section{References}

Egan, K. (1978) What is a plot? New Literary History, 9, 455-473.

Kingsbury, J. D. (1994) The plot of Luke's story of Jesus. Interpretation, 48, 369-378.

Klink III, E. W. (2004) The gospel community debate: state of the question. Currents in Biblical Research, 3, $60-85$.

Matera, F. J. (1987) The plot of Matthew's gospel. The Catholic Bible Quarterly, 49, 233-253.

Whissell, C. (2018) Emotion and Plot in the Premodern English Novel. Common Ground Research Networks: New Directions in the Humanities. 
Whissell, C. (2012). Emotional consistency as evidence of dynamic equivalence among English translations of the Bible. Comprehensive Psychology, 1, 15 (Online journal, no page numbers).

Whissell, C. (2009). Using the revised Dictionary of Affect in Language to quantify the emotional undertones of samples of natural language. Psychological Reports, 105, 1-13.

Whissell, C. (2008). The distinct emotional flavour of Gnostic writings from the early Christian era. Psychological Reports, 102, 213-234.

Wright, T. R. (1984) Narrative: the gospels as fiction. Religious Studies, 20, 389-400.

Figure 1. The emotional plot of the parable of the prodigal son (Luke 15:11-32)

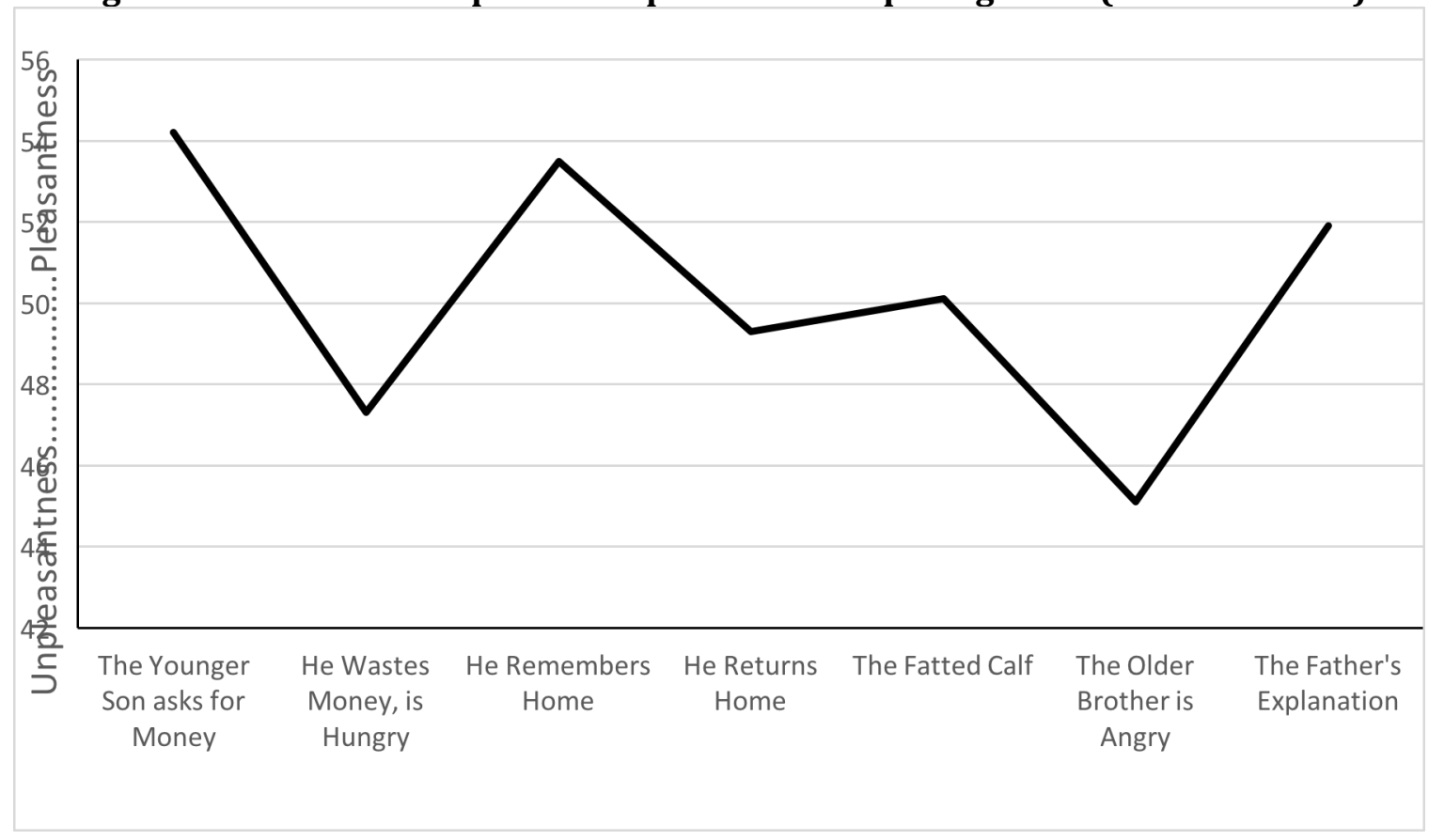

Figure 2. The common emotional plot of the four gospels.

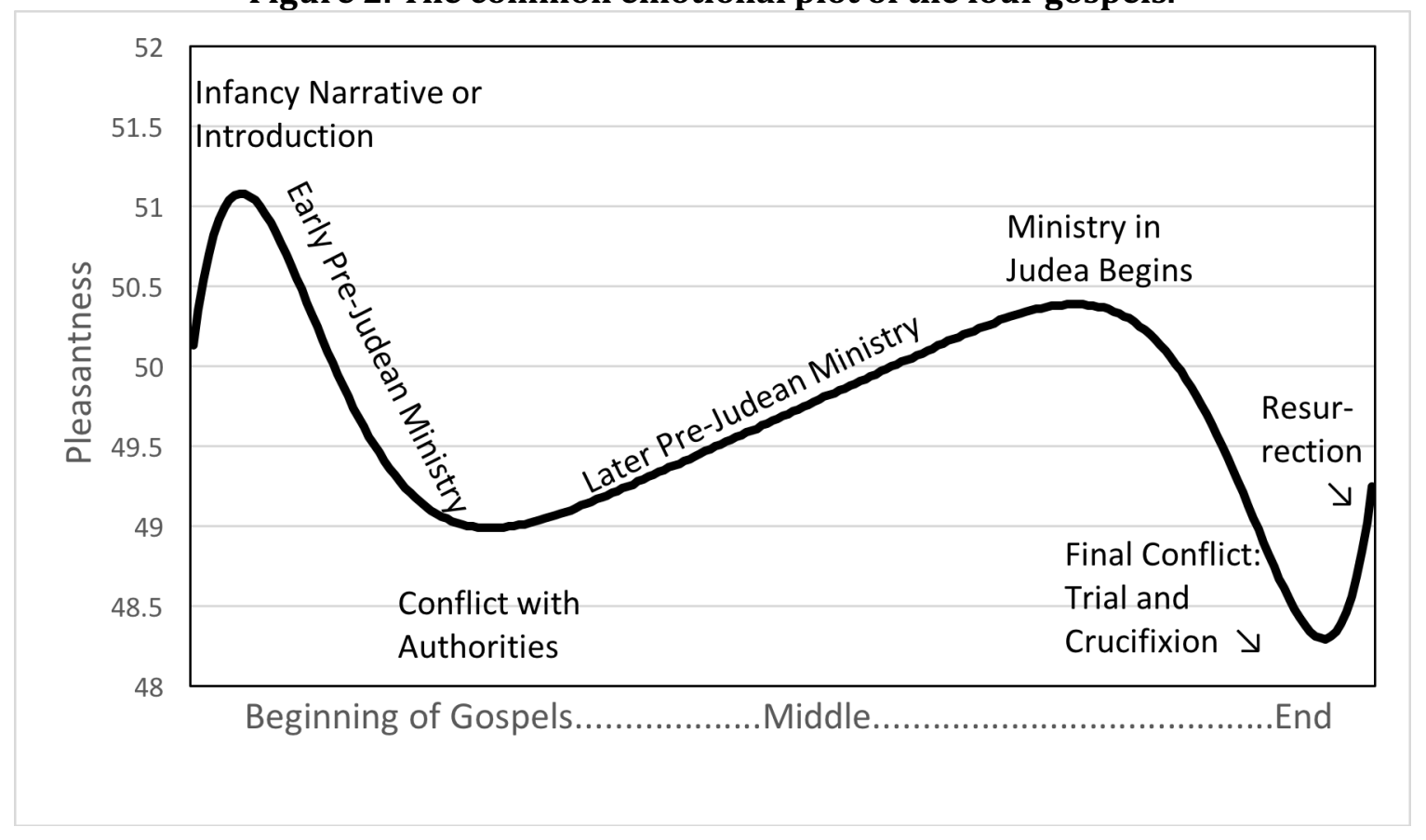


Figure 3 The role of the common emotional plot as a backbone to the variation of emotions within the gospel of Matthew

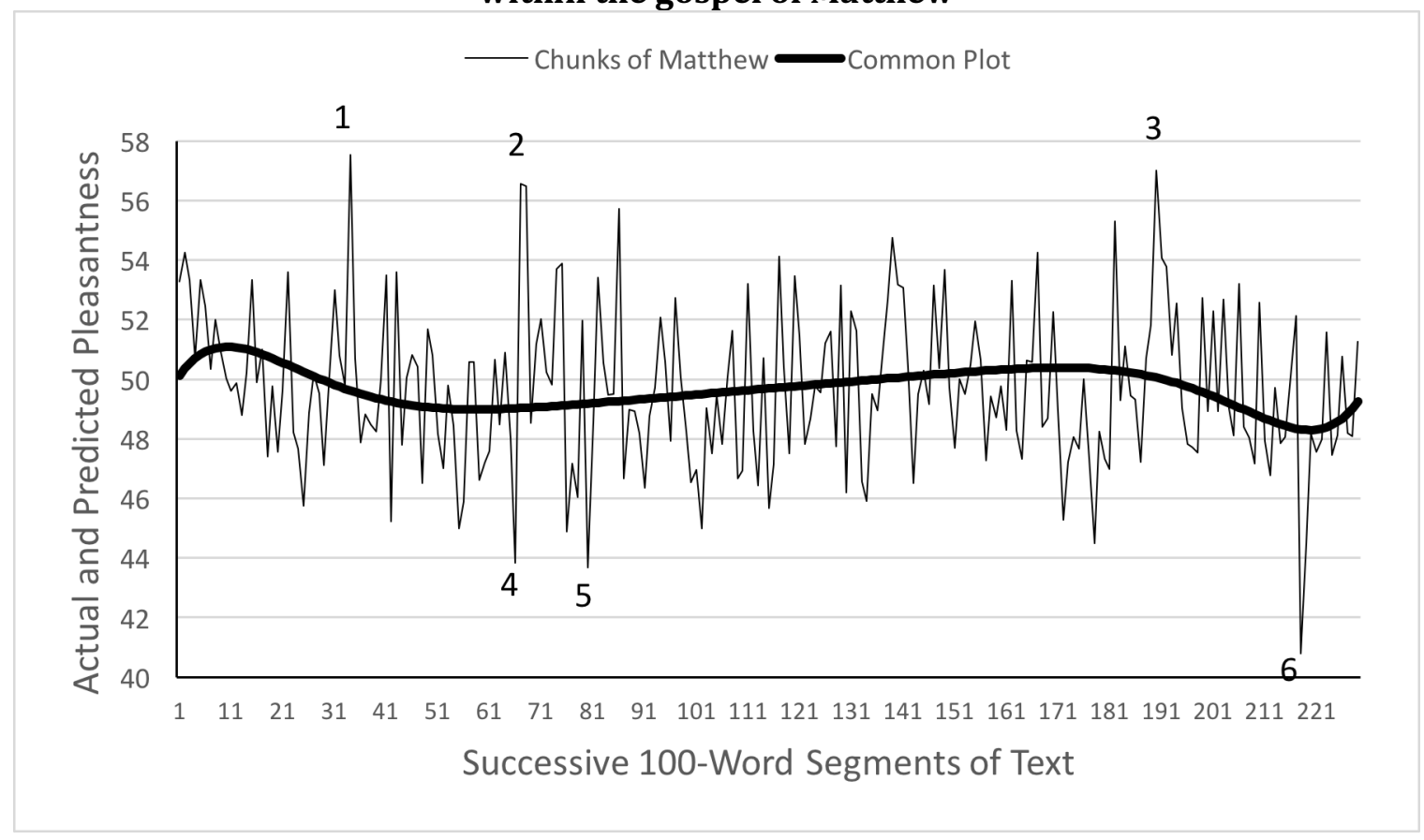

Key Deviations from the Common Backbone for the Gospel of Matthew:

Extremely Pleasant Chunks of Text

1. 6:19-15 The Lord's Prayer.

2. 10:32-41 Jesus describes those who confess him; "Every one who confesses me..."

3. 25:18-22 Parable of the talents; "Well done good and faithful servant..."

\section{Extremely Unpleasant Chunks of Text}

4. 10:23-26 Jesus discusses the coming persecution; whom to fear and not to fear

5. 12:22-26 Pharisees claim Jesus accomplishes his miracles through Beelzebul; "A house divided..."

6. 27:28-31 The crown of thorns; the mockery of Jesus before his Crucifixion

Note that chunks may begin and/or end in the middle of a verse, so that the references above are approximate. 